\title{
“UN GESTE SUFFIT"? UNPACKING THE INCONVENIENT TRUTHS ABOUT AL GORE'S CELEBRITY ACTIVISM
}

\author{
P. David Marshall, Glenn D'Cruz, and Sharyn McDonald
}

\begin{abstract}
The present work interrogates Al Gore's persona as a climate change activist with reference to a process we describe with the neologism "personafication": the act of constructing/presenting a public persona in order to cultivate impressions that enable public figures to consolidate authoritative reputations. The formation of such a commanding persona requires the circulation of three forms of symbolic capital: cultural, celebrity, and reputational capital as well as the performance of overtly theatrical strategies calculated to establish an empathetic relationship between performer and audience. In 2006, former Vice President Al Gore released the award-winning documentary, An Inconvenient Truth. This film subsequently functioned as a catalyst for various forms of climate change activism. This paper unpacks the contradictory ideological and cultural work performed by the film with reference to what we describe as un geste suffit; that is, those gestures that merely perform individual agency in order to connect the formulation of personal ethical identity to communal forms of political activism like environmentalism. Through a close reading of the presentation of Gore's persona in the film itself, and research which tracks the reception and political efficacy of the film, the paper contributes to the growing body of scholarship on the politics of environmental/scientific communication. Finally, we locate our reading of Gore's film within a contemporary context by making reference to the way An Inconvenient Truth is both resistant to and complicit with the environmental policies of the Trump administration.
\end{abstract}

\section{KEY WORDS}

Celebrity Activism; Persona; Al Gore; Climate Change; An Inconvenient Truth (Film)

\section{INTRODUCTION}

This paper unpacks the ideological work performed by Al Gore's environmental activism by tracking and analysing the development of his profoundly complex public persona with a focus on his award-winning film, An Inconvenient Truth (2006), a formative vehicle for what we call Gore's personafication. That is, a process that involves three dimensions: the 'facticity' of persona, the acquisition and display of symbolic capital, and the affective performance of persona.

We do this to better articulate the political dimension of persona studies (Marshall and Henderson 2016), and contribute to the growing body of scholarship on celebrity activism in the fields of cultural studies (see for example Pezzullo 2013), celebrity studies (see for example Littler \& Goodman 2013; Marshall 2013; Turner 2016) and, more specifically, environmental 
communication. In doing this we acknowledge, in the words of Cox and Pezzullo, that "the way we communicate with one another about the environment powerfully affects how we define both it and ourselves and, therefore, how we define our relationships with the natural world" (2016, p. 2). However, we also believe that it is important to pay attention to the complex mechanisms that confer and undermine the authority of public figures such as Gore. Put differently, we argue that the performative dimension of celebrity persona constitutes a hitherto neglected "node" of the "circuit of culture" developed as an analytical methodology by Stuart Hall and his colleagues in the late 1990s (du Gay et al. 1997, pp. xxx-xxxi).

We will frame our analysis of Gore's environmental activism with a discussion of the connections between the performance of individual agency in everyday life and the performance of activism in celebrity culture.

\section{VICE-PRESIDENT 'BORE'}

From 1993-2001, Al Gore was the 45th Vice-President of the United States. Had he not become a prominent environmentalist activist his fame might have faded from collective public memory. In policy terms, he might be remembered as an advocate for universal access to the internet, various environmental causes, and as a staunch defender of Bill Clinton during the Monica Lewinsky scandal. As VP, commentators perceived Gore as an earnest, hardworking, pedantic bore. For example, writing in 2000, the year of Gore's unsuccessful presidential campaign, David Maraniss and Ellen Nakashima of The Washington Post noted that Gore "is often contrasted with the personality of his political patron and White House boss, Bill Clinton, who is considered more extemporaneous" (2000). The Post journalists sought to make public Gore's mediocre academic record, and question Gore's credentials as a tech-savvy candidate. Their article ends with a quote from Gore's then press secretary, Chris Lehane, who states, "This just proves that many of the preconceived notions of Al Gore have been stiff and boring... He in fact has a very rich and well-rounded background--artist, athlete and academic" (in Maraniss \& Nakashima 2000).

The article ignores the fact that Gore wrote a senior year thesis at Harvard University titled 'The Impact of Television on the Conduct of the Presidency, 1947-1969' (Gore, 1969). The thesis itself concerns the way televised presidential press conferences transformed the way that the White House disseminated information under the administrations of Eisenhower, Kennedy, Johnson, and Nixon. The salient point here is that as a former student of television, Gore was aware of the role media play in political life. However, it would be imprudent to claim that the authorship of this thesis alone accounts for Gore's eventual transformation from pedantic bore to dynamic climate change warrior. Nonetheless, it is important to bear in mind that Gore has had a long-standing interest in the relationship between media and political communication, and, as we shall see, this background forms one significant context for understanding the way the performative node of the circuit of culture impacts on the construction of Gore's Persona.

We will return the facticity of Gore's persona later; for the moment we need to acknowledge that we live in the era of celebrity politics. This is a complex relationship that scholars such as Wheeler (2013) have outlined permeates our fields of popular and political culture, and works to reform the way that issues migrate through our mediated world. We need to recognise that it is a time when the relationship between popular culture and politics generates celebrity politicians and political celebrities. Moreover, it is important to acknowledge further that in our relatively new era of social media, we have a different circulation of newsfeeds that challenge the power and conventions of legacy media. As Lance Bennett's work has explored, this increasing personalisation of politics shifts from legacy 
media's constitution of a public "Daily Us" (drawing from Negroponte 1995) to new media's "Daily Me" (Bennett 2016, p. 1; Bennett \& Segerberg 2012, pp. 739-768). This personalization of politics is potentially pushing us into further blending of celebrity and politics, albeit perhaps with a different configuration around issues and personalities.

John Street (2004) makes a distinction between two types of celebrity politicians. The first is an elected representative who has a background in an entertainment industry (Ronald Reagan and Arnold Schwarzenegger, for example). The second is an elected official who seeks celebrity status through association (Tony Blair consorting with pop stars). Of course, people who hold prestigious political office also accrue the trappings of celebrity (Obama is a paradigmatic instance of this kind of celebrity politician). Gore is yet another type of celebrity politician since he draws on his former life as a politician to bolster his credibility while promoting an activist agenda through making films and associating with activist celebrities. This paper argues that Gore's particular brand of celebrity activism draws heavily on his cultivation of a new persona, one that is distinctive from his VP persona. More importantly, Gore's public presentation of self is enmeshed with a form of political activism, which both connects and distinguishes him from the activities of celebrity activists such as Leonardo DiCaprio, for example. It is therefore necessary to examine this form of celebrity activism as a prelude to our account of Gore's personafication. It is also important to stress that we are not making value judgements about the efficacy of celebrity activism per se. In what follows, we contrast the similarities and differences between Gore's activist strategies and those of celebrity activists involved in what Puzzello (2011) calls 'buycott' strategies. That is, a form of consumer activism that involves the purchase of products deemed to be good for the environment. While we are agnostic about the pragmatic value of such actions, we acknowledge that mass consumption of certain kinds of environmentally-friendly products might produce beneficial consequences that are independent of the consumer's ethical commitment to environmental politics. With these caveats aside, the focus of this paper is on the personafication of Gore as a significant moment in the history of climate change communication.

\section{UN GESTE SUFFIT}

Let there be light, or not. Sometime during the 1990s, a concise imperative appeared under an inordinate number of light switches in the public institutions of Ottawa and Montreal: un geste suffit. This exhortation, a sufficient gesture, conveyed the idea that by simply turning off a light, people could make a small contribution to saving electricity. Such a gesture would also contribute, presumably, to both economic efficiency and environmental responsibility. It was also a caring sentiment that at the institutional level attached the institution to the metanarrative of environmentalism and at least pushed individual employees to feel a shared obligation. Meta-narratives have often been linked to capitalism, religion, socialism and the sense of progress attached to modernity (Lyotard 1984); but despite Lyotard's belief that the postmodern condition was marked by an incredulity towards meta-narratives (Lyotard 1984, p. xxiv), it is important to acknowledge that they can continue to function as mechanisms that describe how complex cultural representations flow through narratives that organise the self and society. In this sense, environmentalism is a meta-narrative that provides people with an intelligible structure for everyday life by promoting a set of stories that 'makes sense' of the order of things. On one level, then, environmentalism is a complex scientific discourse that substantiates the reality of global warming, but it is also a gestural narrative that enables individuals to express solidarity with an ethical belief system that confers on them an identity that is indivisibly connected to the meta-narrative of climate crisis. 
The salient point here is not that people are deluded or misguided about the real impact of small performative gestures. Rather, the imperative described above has an ideological function; it addresses people as individuals and communicates the idea that a small individual gesture, like turning off the lights, can meaningfully contribute to averting a climatic cataclysm that is a consequence of complex forces generated by industrialisation, public policy, and capitalism. The act of turning off a light becomes a performative act of individualized agency. Put differently, it is a form of political engagement that possesses an ethical posture and moves through the individual into a collective experience.

But perhaps there is the unsettling feeling amongst those of us who perform such gestures that they merely produce affective sentiments as opposed to concrete political interventions. As we shall see in what follows, we underestimate the political valence of affective sentiments at our peril. We should at least consider whether such acts are merely selfsufficient gestures that do little more than communicate an ethical identity.

\section{CELEBRITY ENVIRONMENTALISM}

Celebrities often use their fame and elevated social status to bring attention to a variety of political issues. Chris Rojek coined the term "celanthropy" to refer "to the voluntary participation of celebrities in humanitarian fundraising, publicity awareness and charity building" (2012, p. 67). Ethical gestures performed by celebrities are different from those performed by "ordinary" people because of their public visibility and reach. This is why most social justice campaigners, especially those concerned with environmental activism, value celebrity activism. Indeed, celebrity environmentalism, an important subset of celebrity activism, has become an increasingly common way for celebrities to engage with the world. For example, in 2003 a public relations firm ordered five Toyota Priuses to chauffeur interested stars to the Oscars. Harrison Ford, Callista Flockhart, Leonardo DiCaprio, Jeff Goldblum, and Cameron Diaz used these vehicles to transport themselves to the $75^{\text {th }}$ Oscars. This gesture may appear ridiculous in some ways. After all, the Prius is a hybrid car, which still uses fossil fuel. However, the mere hint that the electricity that partially powers the car may come from renewable energy resources is enough to convey the stars' concern about conservation. This gesture, which attracted significant media attention, is structurally very similar to un geste suffit. In both cases, a performative gesture communicates concern, and functions as a mechanism to connect an individual to a collective social cause. However, the ethical look of someone like Leonardo DiCaprio is striking in the way it conveys a sense of position and fortitude that has an almost religious dimension to it. More importantly, the spectacle of celebrities aligning themselves with the Prius demonstrates the extent to which celebrity culture and environmental activism are enmeshed in a complex web of relations that cannot be understood without reference to corporate capitalism. Dan Brockington argues that

$$
\begin{aligned}
& \text { the flourishing of celebrity conservation is part of an ever-closer intertwining } \\
& \text { of conservation and corporate capitalism. Companies are greening, with } \\
& \text { varying degrees of sincerity and effectiveness, because being green enhances } \\
& \text { sales. Conservation is becoming more commercial because selling commodities } \\
& \text { provides funds. (Brockington 2009, p. 2) }
\end{aligned}
$$

In other words, Brockington points to a growing symbiotic relationship between corporations and ethical consumers, those people who engage in what Phaedra C. Pezzullo calls "buycotting" (2011). That is, "a concerted effort to make a point of spending money-as well as to convince others to make a point of spending money-on a product or service in the hopes of affirming specific condition(s) or practice(s) of an institution" (Pezzullo 2011, p. 125). Thus, the celebrity endorsement of the Prius is an example of the "buycott", which is obviously a performative 
gesture, writ large. This is not to say that celebrity activism is somehow insincere or ineffective. Rather, it is to accept that activism takes place within a specific ideological context, as we shall see when we examine Al Gore's environmental activism. Moreover, it is important to understand that our consumption of commodities also reflects an ethical posture towards the environment. To reiterate Brockington's point, environmental activism is imbricated within the economic and cultural flows of consumer capitalism, which means that activism is mediated through our consumption of commodities. In a sense, the consumption of commodities-clean energy, hybrid automobiles, organic groceries and so on-help us understand our relationship to other parts of the world. They also help us recognize that even if these items do not originally belong to our domestic world, they become part and parcel of our everyday lives, and give expression to our ideological proclivities. In other words, we make ethical choices in the very act of consumption. The celebrity endorsement of the Prius discussed earlier is a good example of commodity activism. Even though the Prius happens to be a reasonably expensive car, the decision to drive the vehicle performs an ideological function in affirming an ethical position with respect to the environment. The act is structurally identical to the way in which we might choose Fair Trade coffee. In both cases the consumer makes an apparently ethical calculation to determine whether a particular product is harmful to the environment. For example, the production of palm oil decimates wildlife habitats in countries like Indonesia. The salient point in this discussion for our purposes is that such consumer activism, whether performed by celebrities or everyday people, reinforces the belief that activism is primarily a matter of individual action and choice. The major question posed by activists such as Gore concerns individual agency: what can you, as a consumer, do to save the environment? Buy fresh food? Recycle waste? Gore's film, An Inconvenient Truth (2006), , makes a series of such pragmatic consumer oriented suggestions as the credits roll at the end of the movie. Celebrity activism, we contend, with Brockington and others, is a hyper-individual expression. We can detect, in that hyper-expression of individuality, the ideological suppositions that naturalize capitalist consumption to media consumption. So, in a sense, celebrity with its reinforcement of hyperindividuality, is an articulation of a kind of individualized capitalism.

Of course, there are different conceptualisations of agency with respect to global warming. Bruno Latour, for example, argues that non-human agents play a profound role in the climate crisis $(2014 ; 2017$, p. 41). This position is quite foreign to traditional anthropomorphic accounts of agency. In brief, Latour claims that Gaia, the earth itself, functions as an agent that affects all sorts of things (2017, p. 41). Not just humans, but every dimension of plant and animal life. Suffice it say that we are living in the Anthropocene, which is, by definition, the result of collective human agency in the form of toxic industrialisation, collapsing the distinction between geological time and human time through its impact of the environment (Latour 2014; 2017). The question of agency, human or otherwise, is fraught with complications and conundrums. In short, we have argued thus far that while we may be able to make rational choices as consumers, we cannot fully understand how individual human agency connects with the complex set of institutions, discourses, and material forces that operate at global levels, national levels, and even regional levels.

So where does all this leave us with respect to celebrity activism? Is such activism un geste suffit? Are celebrity activists industrial agents? In other words, are they comfortable with consumer capitalism, and committed to a form of commodity activism that expresses individuality entirely in terms of industrial models of agency? What follows in this paper is a critical interrogation of $\mathrm{Al}$ Gore's performance of individualized human agency and his commitment to a form of consumer activism that is consistent with capitalist ideology. We will pay particular attention to Gore's affective embodiment of industrial agency and focus on the ways his activism depends on the construction of an authentic public persona. While Gore may 
or may not be fully conscious of what he is doing, and may or may not be able to even substantiate his position with respect to his public presentation of self, he nevertheless adopts an ethical posture that makes sense in terms of a common-sense notion of individual agency. The question, then, is to determine whether Gore's environmental activism is similar to the un geste suffit that each of us performs when we turn off the lights in the name of conservation. In order to formulate an answer, we need to take a close look at Gore's public persona.

\title{
The Personaficationof Al GoRE
}

Let us state here that any conscious attempt to construct an authoritative and authentic public persona cannot succeed without public consent. Put simply, the construction and presentation of a public self means little if it is not endorsed and accepted by a significant portion of the public. As current research regarding the political in persona studies has reiterated, persona is neither an individual nor collective identity, but instead the negotiation of the individual-and the collective-for the use of an identity in a public and collective world (see Marshall \& Barbour 2015; Marshall \& Henderson 2016). In this sense, all public figures are inherently ambivalent with regard to questions of authority and authenticity, for the celebrity is, among many other things, a polysemic text that can be read in various ways. For example, Al Gore's political credentials probably hold little value for a rabid Trump supporter. Indeed, Gore's political background is more than likely to undermine his authority in the eyes of those with antithetical political sympathies. Graeme Turner echoes this observation in a special issue of the journal Environmental Communication focused on popular culture, when he argues that celebrities are

\begin{abstract}
just as effective at attracting derision as desire, and so it is not surprising that the same ambivalence we find in relation to celebrities in general might affect the public's response to specific celebrities' engagement in projects of celanthropy. High-profile celebrities engaged in major global humanitarian causes, such as Bono, Sting, or Angelina Jolie, have certainly earnt admiration and respect for their activities, but they have also attracted criticism and in some cases even ridicule. (Turner 2016, p 811)
\end{abstract}

This is not to say that there is nothing to be gained from examining the way Gore mobilizes certain discourses and performative strategies to construct an engaging and authoritative public persona. Rather, it is to recognize that qualities like authority and authenticity depend on public recognition. Having said that, let us look more closely at the visible components of Gore's persona with reference to what we call the facticity of persona. That is, those publicly visible qualities and external conditions that define a human being. Our analysis might begin with an enumeration of those qualities and conditions that function as a backdrop to Gore's public persona. With respect to the facticity of his persona, we can say that Al Gore is a white, heterosexual man who served as vice president of the United States under President Bill Clinton, and ran for the presidency himself in the year 2000. He was born into a political family, his father was Senator Albert Gore Snr, and he spent his early years living in Washington D.C. and on the family farm in Tennessee. (The Gore family grew tobacco amongst other crops.) Gore refers to all of these 'facts' in An Inconvenient Truth (2006), for he builds his persona on the back of these self-evident truths about his life :the first section of the film contains a montage of Gore's political career in order to immediately establish his authority as a man engaged in public life for the betterment of his country. However, if we are to more fully understand what we might call the personafication of Al Gore, we need to look at how Gore expands on these biographical facts to create a compelling narrative about the ethical posture he adopts with respect to the environment, for An Inconvenient Truth (2006) is as much about Gore as it is about climate change. 
The neologism, personafication, describes three interconnected processes involved in the creation of an authoritative public persona:

(1) The facticity of persona

(2) The acquisition and display of symbolic capital

(3) The affective performance of persona

We have already dealt with the facticity of persona, so let us turn our attention to the role various forms of symbolic capital play in the construction of an authoritative public persona. Gore's public persona draws on his accumulation of three forms of symbolic capital: cultural capital, celebrity capital, and reputational capitali. Born into a wealthy family, Gore's stocks of cultural capital have always been high. As a graduate of Harvard University, he effortlessly conveys the cultural authority associated with an Ivy League education. Further, Gore's early literary ambitions reveal themselves in his speech patterns: he is extremely articulate, and effortlessly refers to a wide range of scientific and literary texts during his speeches and presentations, and the folksy, southern lilt of his accent stresses rather than diminishes his authority by conveying a friendly informality to his otherwise serious declarations. In his article, 'Celebrity Capital: redefining celebrity using field theory' Olivier Driessens (2013) argues that media visibility is a form of capital that celebrities accrue and convert into other forms of economic or political capital. Driessens (2013) argues that visibility is the key to accumulating celebrity capital, and Gore's high-profile political career coupled with his environmental activism has certainly made him visible to the public. This proactive form of global civic leadership can also be linked to reputational capital. Petrick et al. $(1999$, p. 60) consider reputational capital as intangible value based on stakeholders' perceptions of organisations as responsible corporate citizens solidifying trust, credibility, and reliability. They associate superior leadership with the creation and sustainability of reputational capital (Petrick et al. 1999). As such, we assert that such capital can be bolstered through a public figure's leadership and association with institutions.

It is possible to argue that the American Government's stocks of reputational capital have always been questionable (a point we will return to at the end of this paper). Nevertheless, Gore himself overtly draws on his experience as a politician to lend credibility and an air of authenticity to his activism. Shingler and Wieringa (1998, p. 11) argue that radio hosts are closely aligned with the public reputation of the stations they work for, and often overtly personify their station's image. While Gore's primary affiliation is with a political party and the public offices he held in the Clinton administration, there is little doubt that a significant part of his persona relies on what we might call reputational capital. As previously stated, his film consistently makes reference to Gore's political career in order to consolidate his reputation as a trustworthy source of knowledge. Early in the film Gore declares "I was in politics for a long time. I'm proud of my services" (An Inconvenient Truth 2006). A littler later in the film he states:

When I went to the Congress in the middle 1970s I helped organize the first hearings on global warming, I asked my professor to be the lead-off witness. I thought that would have such a big impact we'd be on the way to solving this problem, but it didn't work out that way. I kept having hearings. In 1984, I went to the Senate and really dug deeply into this issue with science roundtables and the like. I wrote a book about it. I ran for president in 1988 partly to try to gain some visibility for this issue. In 1992 I went to the White House. We passed a version of a carbon tax and some other measures to try to address this. I went to Kyoto in 1997 to help get a treaty that is so controversial, in the US, at least. In 2000 my opponent pledged to regulate the CO2. That was not a pledge that 
was kept. The point of this is all this time you can see what I have seen all these years. It just keeps going up. It is relentless. (An Inconvenient Truth 2006)

This speech consolidates Gore as the quintessential "good guy" politician and a man of action, someone who gets things done through public service. It is also important to underscore that the effectiveness of how a message is received depends on the credibility of the messenger. There are several dimensions of credibility summarized by Roobina Ohanian (1990) as a combination of factors that can include the communicator being trustworthy, demonstrating expertise and being physically attractive. Ohanian developed a source-credibility scale, where attributes are classified under the three dimensions; each can be measured along a scale of extreme opposites, for example "Trustworthy - Untrustworthy" (1990, p. 50). There are several positive personal attributes demonstrated by Gore that help explain why he may persuade people to alter their opinions and ultimately change their behaviour.

An audience who perceives a communicator to be trustworthy has confidence in the speaker (Ohanian 1990, p. 41). Positive attributes that demonstrate someone is trustworthy include being dependable, honest, reliable, and sincere (Ohanian 1990, p. 50). Although Gore was not successful in winning the 2000 U.S. presidential election, he won the popular vote with 500,000+ more votes than George W. Bush received (FactCheck.org 2016, para. 2). As such, it can be surmised that Gore was considered an authoritative candidate with suitable expertise to be placed in this position of trust and power by $50,999,897$ U.S. voters (Federal Election Commission 2001). Although Gore was awarded the Nobel Peace Prize after the release of $A n$ Inconvenient Truth (Borick \& Rabe 2010), the prize provides further validation of his sincerity regarding the climate change issue. Gore's popularity among voters also demonstrates his status as an expert. A former military serviceman, journalist, and politician, Gore can demonstrate that he encompasses several qualities as per Ohanian's scale of expertise including experience, knowledge, and skills (1990, p. 50). Lastly, the attribute of "attractiveness" is characterized by Ohanian as classy, beautiful, elegant, and sexy (1990, p. 50). While attractiveness can be considered subjective, arguably Gore delivered his message with consummate style. The documentary reinforced Gore's strength of appeal by framing him as "a man of good private moral character, a dutiful son, loving father, and loyal sibling...(with) no political aspirations to be served...only shared concerns with the audience" (Olson 2007, p. 99). Gore's source credibility provided appeal for multiple audiences globally, triggering a series of positive outcomes. This brings us to the last feature of the process we are calling personafication in affective performance: those overtly theatrical strategies calculated to establish an empathetic relationship between performer and audience.

There is always a performative dimension to consolidating the authority and authenticity of a public persona, and on the evidence of An Inconvenient Truth alone, Gore is a consummate performer. Unlike the current POTUS, whose authority derives from an archaic model of masculine strength, Gore exudes an aura of authority that is tempered by the cultivation of an extremely accessible and likeable public persona (Gore's concession speech to Bush is an exemplar of graciousness and modesty). Gore also does a great line in selfdeprecation. He has great comic timing and turns his greatest professional and personal disappointment (his loss of the 2000 election) into a running gag. He opens the 'slide show' portion of his film by saying "I'm Al Gore. I used to be the next president of the United States. [laughter and applause from audience] I don't find that particularly funny" (An Inconvenient Truth 2006). He regularly riffs on this particular gag in other presentations such as his TED talks.

Gore's ability to reflect on the past saw a deliberate shift in the way he presented himself. Historically, some of the adjectives describing Gore's attributes, speaking style, and 
presence include pedantic, stiff, boring, pompous, patronising, and condescending (Fallows 2000; Olson 2007, p. 92). Gore's need to be precise or seek perfection had come across as "wooden"; this was also acknowledged by Gore himself in the late 90s (Fallows 2000, para 1). James Fallows concluded that some of the criticism directed at Gore's speaking style was when his political opponents sought to send him off script (2000, para 14). While he was more comfortable speaking in a structured way, over time he repositioned himself as "an aggressive, combative campaigner" adopting an "assertive demeanour" (Fallows 2000, para 22)

James Olson and Graeme Haynes sought to understand how Gore had been so effective "given his prior reputation as a wooden speaker" (2008, p. 200). They ascertain that Gore presents a case using a "powerful speech style" (Olson \& Haynes 2008, p. 205) supported by compelling imagery, statistics, and authoritative scientists, but audiences are further persuaded by Gore's source characteristics. They summarise Gore as credible, attractive, and powerful linking these to his personal attributes: intelligent, articulate, humorous, trustworthy, authoritative, honest, charismatic and likeable (Olson \& Haynes 2008, p. 204). This depiction is reinforced by Shaun O'Connell (2015, pp. 11-12) who declares that “Gone was the Gore of stilted, Senatorial rhetoric; instead the Gore persona who narrates this film is a relaxed, often witty sincere, straight-talking man" and he "draws on the authority of his standing as a political celebrity, his political experience and awareness, as well as his family history in a foregrounding of personality that humanizes the topic".

The presentation of Gore in 2006 shifts gears, rhetorically speaking. Drawing on his early interest in literature (he originally had ambitions to become a novelist), Gore voices the lyrical commentary that accompanies the pastoral montage that opens the film. His rhetorical intent is clear: this is what we are destroying, folks! The actual slide show commences with commentary on images of the Earth taken by astronauts. Once again, the rhetorical intent invokes a sublime conception of the Earth, which foregrounds the planet's fragility. The salient point here is that Gore is a nimble performer capable of mobilising a wide range of performative strategies-comedy, lyricism, and an almost religious form of sublime mysticism-to pave the way for his presentation of the science of climate change, a notoriously complex topic that resists simplification (a fact ruthlessly exploited by climate sceptics). Having established his credentials and personality, Gore moves on to the business of explaining global warming to his presumably lay audience.

We do not have the luxury of analysing the film in minute detail, but we do need to address the question of Gore's attempts to engage his audience on both a cerebral and an emotional level. DiFrancesco and Young argue that the film's

visual imagery is essential for making climate change 'consumable' for a sizable fraction of the population. While images are often said to embody complexity (being worth the proverbial thousand words), media theory tells us that they also reduce complexity by providing interpretive frames or narratives that selectively blend fact and emotion. (DiFrancesco \& Young 2011, p. 518)

While awash with a welter of facts about climate science that are cleverly presented through graphic and dramatic illustrations, Gore and the creative team responsible for the film realize that they need to not just perform caring for the environment, but they need to inspire their audience to become activists. This is why the film interrupts the slide show with a series of reflective monologues that Gore delivers about his personal struggles and emotional traumas, including the 2000 election: "Well, that was a hard blow. But what do you do? You make the best of it. It brought into clear focus, the mission that I had been pursuing for all these years. I started giving the slide show again" (An Inconvenient Truth 2006). 
The monologue concerning the near death of one of his sons provides personal revelations about Gore's realization that life is fragile and precious; another is about the death of his sister from lung cancer. This tragic event caused the Gore family to stop farming tobacco. Delivered in suitably mournful, hushed tones, Gore is essentially talking about making a difficult ethical choice in the face of another inconvenient truth about the connection between smoking and lung cancer. Gore's sister was a life-long smoker, and the family's realization that they were complicit in her suffering due to their cultivation of tobacco resulted in their abandoning tobacco farming at some financial expense. Each anecdote conveys a highly personal trauma, which invites an empathetic response from the audience. Rhetorically, the film uses personal trauma to elicit an emotional connection to its subject matter. The audience needs to feel a personal connection to the consequences of global warming if they are to respond to the film by making their own set of ethical choices, by choosing personal behaviours that reduce energy consumption for example. Conventional drama is primarily about eliciting some kind of affective audience response, which is why we ignore the performative dimension of Gore's presentation of self at our peril.

\section{The Affects of Al Gore's Climate Change Warrior Persona}

Having established the centrality of Gore's persona to the film, we must now look at its reception. On one level, it is difficult to dispute the film's success as both a film and as an inspiration for those people convinced by its message. An Inconvenient Truth received thirtytwo awards and ten additional award nominations, including the Academy Award for Best Documentary in 2007 (IMBd c. 2016). Moreover, the documentary earned US $\$ 25$ million at the box office (Borick \& Rabe 2010, p. 785). The documentary's reach extended even further as it was shown for free in schools in several countries (BBC News 2007; Olson 2007). Additionally, we can measure the success of the documentary with reference to the activism it has directly inspired. By encouraging individual political agency as well as changes in personal behaviour, Gore's film suggests that grassroots activism can change public policy (Olson 2007, p. 100). It is clear that An Inconvenient Truth became the catalyst for a movement that saw thousands of volunteers step up to replicate Gore's message within their own communities. In May 2016, The Climate Reality Project sought to mark the 10-year anniversary of the release of An Inconvenient Truth. They set up a hashtag on Facebook to encourage people, regardless of age, to share how the film changed them. We can summarize their responses with reference to four broad themes: (1) We woke up, (2) We grew up understanding the facts-and taking action, (3) We changed it up, and (4) We spoke up and taught others (The Climate Reality Project 2016). Some representative statements include:

Wow! \#ait10 was instrumental in what has become my passion. A part of @ClimateReality since 2007. Thanks @algore. (Contributor A)

\#ait10 Its been 10 years already! I first watched it when I was in class 10, 6 years ago! And now I am a \#climateleader for our Environment. (Contributor B)

Ten years ago changed my career to engineer batteries for hybrid and electric cars. Bought a Chevy Volt. EV enthusiast. \#ait10. (Contributor C)

I went to the Climate Reality training in Toronto ... I have written letters to our local paper, to the prime minister. I have taken part in Twitter chats with [Climate Reality] and the UN, where some of the things I have said have reached over 7,000 people! [And] I have appeared on a local radio station with another lady who was trained in Toronto ... and just when I'm feeling like I should 
maybe slow down a little, someone will thank me or come up and talk to me about something I have said. This gives me hope that maybe, just maybe I am helping in this battle in a small way. (Contributor D) (The Climate Reality Project 2016)

Extending Olson's (2007, p. 90) view that An Inconvenient Truth was a form of "social advocacy that successfully galvanized ordinary people" is the resultant initiative, Climate Change Reality Leadership Corps. To date, 12,322 volunteers across 137 countries have been trained to deliver the climate change message, representing a growth of over 1,500 volunteers since the ten-year anniversary (The Climate Reality Project c.2018). These environmental ambassadors leverage credibility from Gore's film to create their own representations as experts in this climate space. The diversity of ages, occupations, and locations of subsequent 'climate leaders' allows the unified message to reach a variety of audiences, large and small, through a variety of media.

The function of these climate leaders provides a contemporary focus to past literature on the role of significant influencers or "champions" (Reynolds 2008, p. 9) who are a fundamental component in the resolution of social and environmental issues. Champions are considered agents of change that seek to resolve issues (Reynolds 2008, p. 9). Within an organisation, champions are pivotal in identifying and highlighting issues they feel passionate about, which can encourage decision makers to prioritize issues (Madden, Scaife \& Crissman 2006, p. 53). The Climate Reality Project has become an organisation that helps individuals harness their passion and provide them with expertise to help deliver key messages to a variety of audiences. We can find a range of profiles representing the diversity and motivations of Climate Reality Leaders on The Climate Reality Project web pages.

Is it possible to classify Gore as a pioneering climate change warrior? He has been able to keep the climate change conversation alive by establishing The Climate Reality Project. Studies examining social alliance phenomena attribute several characteristics found among key influencers or leaders championing a cause: credibility, entrepreneurial initiative, energy, resourcefulness, and being well-connected (Berger, Cunningham \& Drumwright 2006; Hartman, Hofman \& Stafford 1999). United by a common purpose, several celebrities have become spokespersons for the environment, which helps The Climate Reality Project leverage off their individual personas. Some notable celebrity advocates include Mark Ruffalo, Emma Thompson, Arnold Schwarzenegger, Don Cheadle, Jessica Alba, Robert Redford, Ian Somerhalder, Pharrell Williams, and Leonardo DiCaprio (The Climate Reality Project 2015). Strength and expansion can be drawn from the collaborative efforts when actors unite. Not only do these celebrity activists harbour their own source credibility and subsequent influence, but when united as a single voice, they help to sustain momentum of an issue of this magnitude. This form of collaboration around an issue supports the notion of social responsibility clusters, whereby organisations and individuals "form around a social issue and act as catalysts in soliciting further support and generating positive change" (McDonald 2014, p. 344).

Tangible outputs resulting from An Inconvenient Truth includes this unity of celebrity activists, leadership/volunteer training, and geographic reach. Collectively, this demonstrates an innovative approach and mechanism to expand and maintain visibility of the issue. Through advocacy, these additional celebrity and climate leader voices extend the time that audiences and advocates remain enthusiastic about solving the issue. While the need to reduce environmental impacts had been in the public's consciousness long before the release of $A n$ Inconvenient Truth (2006), the film enthused new audiences about the possibility of finding solutions to global warming. Enthusiasm to demonstrate individual advocacy and assert grassroots pressure on policy makers provides a strong demonstration of the influence the film and Gore have helped advance (Olson 2007, p. 105). With the knowledge that people can 
become complacent, and other issues take prominence, the evolutionary tactics deployed by The Climate Reality Project have helped sustain climate change as a significant issue.

This is all well and good, but how do we account for the fact that now Donald Trump is the President of the United States, many of the practical policy initiatives implemented by the Obama administration have already been dismantled? And what is the status of the ethical gestures advocated by Gore's film in a communications context that must contend with social media trolls, fake news, and "alternative facts"? It has never been more crucial to be mindful of the complexities involved in communicating climate change. Indeed, a large number of scholars from a variety of different disciplines are attempting to unpack the rhetoric or politics of climate change communication. The situation, according to much of this research, is dire and Trump's election is a symptom of our collective failure to communicate climate science effectively. Pearce et al. observe that

Around 2009, there still was hope that 'better' climate change communication would increasingly and relatively straightforwardly lead to better global and local climate change policies with popular uptake of such policies. Such hopes have been dented in the intervening years and public interest in climate change has dwindled, at least as measured through trends for search terms on Google. (Pearce et al. 2015, p. 613)

Moreover, they point out that the climate change debate is being conducted in new media, which facilitate immediate two-way exchanges that require a different approach to analysing public opinion. It also requires us to admit that the debate is now primarily political, as opposed to being scientific-Pearce et al. argue that "a content analysis of articles published in the New York Times found "a gradual decline in the volume of material within the 'Science' topic and an expansion of themes classified under the 'Politics' topic' between 1995 and 2010" (2015, p. 615). It is important to underscore that while Gore may see his political career as an asset in the fight against indifference towards the impending climate change apocalypse, not everyone shares this view. Smith and Leiserowitz (2012), in their paper on the rise of global warming scepticism, actually identify Gore's political career as a significant liability:

Americans associate global warming with former Vice President Al Gore, whom some of them intensely dislike. Their negative affect for Gore thus becomes associated with "global warming" despite the fact they may know little to nothing about the risks. Finally, at a neurological level affective responses typically occur prior to conscious awareness or cognitive processing, and subsequent cognitive processing draws substantially upon these prior feelings to decide whether to pay attention, how to interpret the stimulus, and especially to prime the body for action before the threat has been analytically identified and labelled. (Smith \& Leiserowitz 2012, p. 1029)

This study provides a sober corrective to those who may view An Inconvenient Truth (2006) as a wholly persuasive piece of environmental activism. The point we need to absorb is that rational argumentation, and the presentation of scientific facts, no matter how well articulated or aesthetically pleasing, do relatively little to convince people to change their minds about the real threat of a climatic cataclysm. Finally, there is also the fact that Gore's brand of activism, especially in its 'practical' consumerist guise, fails to contest the one major inconvenient truth that lies at the heart of the climate change debate: ethical consumerism alone will not provide a solution to the warming of the planet.

Raising this issue, which in bold terms is tantamount to saying that capitalism is the root cause of our present malaise, does not automatically dismiss Gore's sincerity. It does, however, 
demand that we consider Zizek's proposition that "the state political elites serve capital" (2010, p. 334). Moreover, any market-based solution to climate change, for Zizek, is delusional. Naomi Klein makes a similar argument, in a different register, in her book This Changes Everything, when she writes that looking for "new ways to privatize the commons and profit from disaster is what our current system is built to do; left to its own devices, it is capable of nothing else" (2014, p. 9). Yet this is essentially Gore's major solution to the problem. It is worth noting that Jason W. Moore (2017) among others argues that the term 'Captialocene' captures a more accurate causal narrative concerning the present ecological crisis. Towards the end of the film, emboldened by a state of patriotic fervor, Gore declares:

We have everything we need, save perhaps political will. In America, political will is a renewable resource. We have the ability to do this. Each one of us is a cause of global warming, but each of us can make choices to change that with the things we buy, with the electricity we use, the cars we drive. We can make choices to bring our individual carbon emissions to zero. The solutions are in our hands. We just have to have the determination to make them happen. ( $A n$ Inconvenient Truth 2006)

Again, with ethical consumption, un geste suffit. It also seems that "political will" is a scarce resource in today's world. Zizek, in his book, Living in the End Times, repeats Fredric Jameson's observation that "it is easier to imagine a total catastrophe which ends all life on earth than it is to imagine a real change in capitalist relations-as if, after a global cataclysm, capitalism will somehow continue" (2010, p. 334). As President Trump wreaks havoc on the environment we need to seriously consider whether market solutions are capable of solving the crisis of climate change, or whether the various exhortations to publicly perform our ethical affiliations is akin to rearranging deckchairs on the Titanic.

\section{CODA: AN INCONVENIENT SEQUEL (2017)}

Directed by Jon Shenk and Bonni Cohen, An Inconvenient Sequel: Truth to Power (2017) premiered at the 2017 Sundance Film Festival on January 19th, where it reportedly received two standing ovations. (The film was released in cinemas in July of 2017). Shenk, in a pre-release publicity video, points out that a lot has changed in the decade since the original film was made (in Siegel 2017). On the one hand, the climate change crisis has deepened, and many of Gore's speculations about its impact on the environment have come to pass. For example, his claim that the site of the new World Trade Center in New York could be submerged by rising water levels occurred as a consequence of Hurricane Sandy in 2012. On a brighter note, renewable energy technologies (solar, wind, and battery storage) have become more sophisticated and now, arguably, present hitherto unimagined solutions to the crisis. They also represent new economic opportunities for astute investors. According to its directors, the film eschews the high-tech slide show format of the first film for a cinéma vérité aesthetic. Cameras follow Gore as he plays the role of an impassioned 24/7 climate change warrior. He also reprises his role as the slightly goofy, regular guy who tells 'Dad jokes' to bolster his self-deprecating persona. This time around, Gore is even more explicitly theatrical, especially in his closing monologue, which quotes Martin Luther King extensively and establishes his work as equal with the major social causes of the last two centuries as well as exhorting us not to despair since despair can be paralysing. Indeed, the filmmakers use the discourse of drama to talk about the film's strengths, which can be found in Gore's lone-crusader activities as well as in the dramatic tension between the escalating climate crisis and the antipathy expressed towards this imminent disaster by the film's primary villain, President Donald Trump. The film consolidates Gore's activist persona by documenting his behind-the-scenes negotiations at the 2015 Paris Climate conference, and 
leading communication workshops for climate leadership advocates. These sequences confirm that Gore addresses the environmental crisis by operating at two levels. His celebrity persona opens doors to the highest levels of global politics, where he uses his celebrity capital to argue his case. And he also mobilises his celebrity persona at a grass roots level.

On the $5^{\text {th }}$ December 2016, Gore met with then president-elect Trump. Details of the meeting are scant. "I had a lengthy and very productive session with the president-elect," Gore told reporters after the meetings. "It was a sincere search for areas of common ground. I had a meeting beforehand with Ivanka Trump. The bulk of the time was with the president-elect, Donald Trump. I found it an extremely interesting conversation, and to be continued, and I'm just going to leave it at that," he added. (Halper \& Rosner 2016). Unfortunately, Gore did not have to wait too long to see where Trump actually stood on the issue of global warming. It would be remiss to dismiss Gore's activism as a form of celebrity vanity, yet we need to be attentive to the contradictions that mark the personafication of Gore within the context of 'Trump's America'. It is too early to tell how the former Vice President's persona will function in the era of 'fake news' and 'alternative facts'. And we will have to wait and see whether An Inconvenient Sequel can connect with enough of its audience to make a difference to their everyday actions with respect to performing or exceeding un geste suffit.

\section{END NOTES}

i The concept of different forms of capital emerges from Pierre Bourdieu's work in Distinction (2010). We have elaborated the distinctions among cultural, reputational, and celebrity capital, drawing our reading of reputation from Petrick et al. (1999) and Doorley and Garcia (2015), cultural capital specifically determined by modes of distinction and differentiation of class fractions as Bourdieu developed, and celebrity capital derived from Driessens' development of this formation of power and drawing on the related work of Hunter, Burgers, and Davidsson (2009).

\section{WORKS CITED}

An Inconvenient Sequel: Truth to Power 2017, film, Dir. Bonni Cohen and John Shenk, Paramount. An Inconvenient Truth: A Global Warning 2006, film, Dir. Davis Guggenheim, Paramount.

BBC News 2007, 'Gore Climate Film's Nine “Errors”, BBC News, 11 October, retrieved 20 November 2016, <http://news.bbc.co.uk/2/hi/7037671.stm>

Bennett, WL 2016, News: The politics of illusion, University of Chicago Press.

Bennett, WL \& Segerberg, A 2012, 'The logic of connective action: Digital media and the personalization of contentious politics', Information, Communication \& Society, vol. 15, no. 5, pp. 739-68.

Berger, I. E, Cunningham, P. H \& Drumwright, M.E 2006, 'Identity, identification, and relationship through social alliances', Journal of the Academy of Marketing Science, vol. 34, no. 2, pp. 128-137, doi: 10.1177/0092070305284973

Borick, C.P \& Rabe, B.G 2010, 'A reason to believe; examining the factors that determine individual views on global warming', Social Science Quarterly, vol. 91, no. 3, pp. 777-800, doi: 10.1111/j.1540-6237.2010.00719.x

Bourdieu, P 2010, Distinction : a social critique of the judgement of taste, Routledge classics., Routledge, London.

Brockington, D 2009, Celebrity and the Environment: Fame, Wealth and Power in Conservation, Zed, London \& New York. 
Cox, R \& Pezzullo, P. C 2016, Environmental Communication and the Public Sphere, $4^{\text {th }}$ edn, Sage, Newbury Park, CA.

DiFrancesco, D. A \& Young, N 2011, 'Seeing Climate Change: The Visual Construction of Global Warming in Canadian National Print Media', Cultural Geographies, vol. 18, no. 4, pp. 517536, doi: https://doi.org/10.1177/1474474010382072

Driessens, 0 2013, 'Celebrity Capital: Redefining Celebrity Using Field Theory', Theory \& Society, vol. 42, no. 5, pp. 543-560, doi: https://doi.org/10.1007/s11186-013-9202-3

Doorley, J, \& Garcia, H.F 2015, Reputation management, The Key to Successful Public Relations and Corporate Communication, 3rd edn. Routledge, New York.

Du Gay, P, Hall, S, Janes, L, Mackay, H, \& Negus, K 1997. Doing Cultural Studies: The Story of the Sony Walkman, Sage/Open University Press, London.

FactCheck.org, 2016, Popular Vote and the Electoral College, FactCheck.org, retrieved 30 January 2017, 20 November 2016,< https://www.factcheck.org/2016/11/popular-vote-andthe-electoral-college/>.

Fallows, J 2000, 'An Acquired Taste', The Atlantic, retrieved 30 January 2017, https://www.theatlantic.com/magazine/archive/2000/07/an-acquired-taste/378263/.

Federal Election Commission 2001, 2000 presidential popular vote summary for all candidates listed on at least one state ballot, Fec.gov, retrieved 20 November 2016, $<$ http://www.fec.gov/pubrec/fe2000/prespop.htm>:

Gore, A 1969, 'The impact of television on the conduct of the presidency, 1947-1969: a thesis', Harvard College.

Halper, D, \& Rosner, E 2016, 'Al Gore Goes to Trump Tower for Meetings with Ivanka, Donald', 5 December, New York Post. Retrieved 30 October 2018, < https://nypost.com/2016/12/05/al-gore-goes-to-trump-tower-for-a-sit-down-withivanka/>

Hartman, C. L, Hofman, P.S. \& Stafford, E. R 1999, 'Partnerships: a path to sustainability,” Business Strategy and the Environment, vol. 8, no. 5 (1999): 255-266, doi: 10.1002/(SICI)1099-0836(199909/10)8:5<255::AID-BSE214>3.0.CO;2-0

Hunter, E.J., Burgers, J.H., Davidsson, Per. 2009, 'Celebrity capital as a strategic asset: Implications for new venture strategies', in G.T. Lumpkin, Jerome A. Katz (eds), Entrepreneurial Strategic Content (Advances in Entrepreneurship, Firm Emergence and Growth, Volume 11) Emerald Group Publishing Limited, pp.137 - 160.

Klein, N 2014, This Changes Everything: Capitalism Vs The Climate, Simon and Schuster, New York.

Latour, B 2014, 'Agency at the Time of the Anthropocene', New Literary History, vol. 45, no. 1, pp. 1-18, doi: $10.1353 /$ nlh.2014.0003

- 2017, Facing Gaia: Eight Lecture on the New Climatic regime, Translated by Catherine Porter, Polity Press, Cambridge.

Littler, J \& Goodman, M 2013, 'Celebrity Ecologies: Introduction', Celebrity Studies, vol. 4, no. 3, pp. 269-276, doi: https://doi.org/10.1080/19392397.2013.831623

Lyotard, J 1984, The Postmodern Condition: A Report on Knowledge, University of Minnesota Press, Minneapolis.

Madden, K, Scaife, W \& Crissman, K 2006, 'How and why small to medium size enterprises (SMEs) engage with their communities: an Australian study', International Journal of Nonprofit and Voluntary Sector Marketing, vol. 11, no. 1, pp. 49-60, doi; $10.1002 /$ nvsm.40

Maraniss, D \& Nakashima, E 2000, 'Gore's Grades Belie Image of Studiousness', The Washington Post, 19 March, https://www.washingtonpost.com/archive/politics/2000/03/19/gores-grades-belieimage-of-studiousness/5da4b9e3-a017-4dd5-9bb5bfc68f0b4eb5/?noredirect=on\&utm term $=.3609340 \mathrm{f} 2 \mathrm{afe}$

Marshall, P.D 2013, 'Personifying Agency: The Public/Persona/Place/Issue Continuum', Celebrity Studies, vol. 4, no. 3 , pp. 369-71, doi: https://doi.or10.1080/19392397.2013.831629 
Marshall, P. D \& Barbour, K 2015, 'Making Intellectual Room for Persona Studies: a new consciousness and a Shifted Perspective', Persona Studies, vol. 1, no. 1, pp. 1 - 12, doi: http://dx.doi.org/10.21153/ps2015vol1no1art464

Marshall, P. D, \& Henderson, N 2016, 'Political Persona 2016: An Introduction', Persona Studies, vol. 2, no. 2, pp. 1-18, doi: http://dx.doi.org/10.21153/ps2016vol2no2art628

McDonald, S 2014, 'Social Responsibility Clusters Arising From Social Partnerships', Social Responsibility Journal, vol. 10, no. 2, pp. 331-34, doi: https://doi.org/10.1108/SRJ-122012-0152

Moore, J.W 2017, 'The Capitalocene, Part I: on the nature and origins of our ecological crisis', The Journal of Peasant Studies, vol. 44, no. 3, pp. 594-630, doi: https://doi.org/10.1080/03066150.2016.1235036

Negroponte, N 1995, Being digital, 1st edition, Knopf, New York.

O'Connell, Shaun. 2015, 'Climate. A Period of Consequence: Environmental Literature of 2006, New England Journal of Public Policy, vol. 28, no. 1, Article 6.

Ohanian, R 1990, 'Construction and Validation of a Scale to Measure Celebrity Endorsers' Perceived Expertise, Trustworthiness, and Attractiveness', Journal of Advertising, vol. 19, no. 3 pp. 39-52.

Olson, K. M 2007. Rhetorical Leadership and Transferable Lessons for Successful Social Advocacy in Al Gore's an Inconvenient Truth. Argumentation and Advocacy, vol. 44, no. 2, pp. 90 - 109, doi: https://doi.org/10.1080/00028533.2007.11821680

Olson, J. M. \& Haynes G.A 2008, 'Persuasion and Leadership', in J.B. Ciulla, D. R. Forsyth, M. A. Genovese, G. R. Goethals, L. Cox Han, and C. L. Hoyt (eds). Leadership At The Crossroads, Praeger, Westport, Conn., pp. 119-212.

Pearce, W, Brown, B, Nerlich, B \& Koteyko, N 2015, 'Communicating climate change: conduits, content, and consensus', WIREs Climate Change, vol. 6, no. 6, pp. 613-626, doi: 10.1002/wcc.366

Petrick, J. A, Scherer, R.F, Brodzinski, J.D, Quinn, J. F \& Ainina, M. 1999, 'Global leadership skills and reputational capital: Intangible resources for sustainable competitive advantage', Academy of Management Executive, vol. 13, no. 1, pp. 58-69, doi: 10.5465/AME.1999.1567322.

Pezzullo, P. C 2011, 'Contextualizing Boycotts and Buycotts: The Impure Politics of ConsumerBased Advocacy in an Age of Global Ecological Crises', Communication and Critical/Cultural Studies, vol. 8, no. 2, pp. 124-145, doi: https://doi.org/10.1080/14791420.2011.566276

- 2013, Cultural Studies and Environment Revisited, Taylor and Francis, London.

Reynolds, F 2008, To Examine Programs That Assist Vulnerable and Complex Chronically Homeless People, The Winston Churchill Memorial Trust of Australia, Mercy Foundation, retrieved 6 February 2017, $<$ http://www.mercyfoundation.com.au/ uploads/pdf/Churchill-Report-FelicityReynolds.pdf

Rojek, C.2012, Fame Attack: The Inflation of Celebrity and Its Consequences, Bloomsbury, London. Shingler, M \& Wieringa, C 1998, On Air: Methods and Meanings of Radio, Arnold Publishers, London.

Siegel, T 2017, 'Al Gore on His 'Inconvenient Truth' Sequel, Private Donald Trump Talks, 'Consoling' Hillary Clinton', The Hollywood Reporter, 18 January, retrieved 7 March 2017, $<$ http://www.hollywoodreporter.com/features/al-gore-his-inconvenient-truth-sequelprivate-donald-trump-talks-consoling-hillary-clinton->

Smith, N \& Leiserowitz, A 2012, 'The Rise of Global Warming Skepticism: Exploring Affective Image Associations in the United States Over Time', Risk Analysis, vol. 32, no. 6 pp. 10211032, doi: 10.1111/j.1539-6924.2012.01801.x

Street, J 2004, 'Celebrity Politicians: Popular Culture and Political Representation', British Journal of Politics and International Relations, vol 6, pp. 435-452, doi: https://doi.org/10.1111/j.1467-856X.2004.00149.x 
The Climate Reality Project 2015, Nine Celebrities Changing the Conversation on Climate Action, The Climate Reality Project, retrieved 20 November 2016, <https://www.climaterealityproject.org/blog/nine-celebrities-changing-conversationclimate-action? ga=1.21698239.547116828.1448423088>

- 2016, Four Ways 'An Inconvenient Truth' Changed Peoples' Lives, The Climate Reality Project, retrieved 20 November 2016 <https://www.climaterealityproject.org/blog/four-waysinconvenient-truth-changed-lives $>$

- 2018, Climate Reality Leadership Corps, The Climate Reality Project, retrieved 17 February 2018<https://www.climaterealityproject.org/leadership-corps>

Turner, G 2016, 'Celebrities and the Environment: The Limits to Their Power', Environmental Communication, vol. 10, no. 6 pp, 811-814, doi: https://doi.org/10.1080/17524032.2016.1209327

Wheeler, M 2013, Celebrity Politics, Wiley, Hoboken NJ.

Zizek, S 2010, Living in the End Times, Verso, London. 